\title{
Investigation of the mechanism of phytate-modified biochar-catalyzed persulfate degradation of Ponceau 2R
}

\author{
Li Hua $^{1} \cdot$ Taozhi Cheng $^{1} \cdot$ Zhiyong Liang $^{1} \cdot$ Ting Wei $^{1}$
}

Received: 17 September 2021 / Accepted: 31 December 2021

(c) The Author(s) 2022

\begin{abstract}
The mechanism of oxidation and degradation effect of phytate-modified biochar catalyzed persulfate on Ponceau 2R was investigated. Chemical-structural properties of phytate-modified biochar, such as surface morphology and surface oxygencontaining functional groups were characterized. The results suggest that modified biochar has better oxidation performance than unmodified biochar, and the modified biochar generated at $500{ }^{\circ} \mathrm{C}$ pyrolysis temperature can catalyze peroxymonosulfate (PMS) system with high efficiency, in large $\mathrm{pH}$ and temperature scope. And the degradation mechanism of Ponceau 2R by biochar-catalyzed PMS generation (BC-PMS) system was researched. It revealed that PBC300 (phytate-modified biochar pyrolyzed at $300{ }^{\circ} \mathrm{C}$ ), PBC500 (phytate-modified biochar pyrolyzed at $500{ }^{\circ} \mathrm{C}$ ), and PBC700 (phytate-modified biochar pyrolyzed at $700^{\circ} \mathrm{C}$ ) may have metaphosphoric acid linked to oxygen atoms and metaphosphoric acid linked in a bridging manner on the surface of biochar, catalyzing the production of hydroxyl radicals by PMS. PBC700 catalyzes the production of singlet oxygen by PMS through its structural defects, and singlet oxygen is the main catalytic product of PBC700.
\end{abstract}

\section{Highlights}

- Changes in phytate modified biochar facilitate electron transfer.

- Modified biochar was more effective than unmodified biochar in treating Ponceau 2R.

Keywords Biochar $\cdot$ Ponceau 2R $\cdot$ Persulfate oxidation

\section{Introduction}

The increasing level of human production is accompanied by the emission of many organic and inorganic pollutants into the environment (Shadi et al. 2021). Ponceau 2R is a synthetic azo dye derived from coal tar, which can cause toxic diseases such as degenerative liver lesions and cirrhosis in humans. Ponceau $2 \mathrm{R}$ plays an irreplaceable role in the dyeing industry (Zhang et al. 2017). However, a large amount of high concentration organic wastewater is generated in the process of its use, in which the aromatic compounds

Li Hua

tuliphua@126.com

1 College of Environmental Science \& Technology, Shaanxi University of Science and Technology, Xi' an 710021, Shaanxi, China
- The reason for phytate-modified biochar to catalyze PMS may be the metaphosphoric acid. are more carcinogenic, causing serious harm to the water ecosystem. Therefore, it attracts much attention. In the treatment of high concentration organic wastewater, advanced oxidation technology (Ahmed et al. 2017; Liu et al. 2021) is considered to be a kind of highly efficient treatment means, using transition metals, such as $\mathrm{Cu}, \mathrm{Fe}$, etc. to catalyze and create a generation of a large number of free radicals to destroy the structure of organic matter, and achieve efficient degradation (Wang et al. 2022).

Biochar, as a porous solid material containing carbon, can be produced by pyrolysis of domestic wastes such as sludge, bones, straw, etc. under anoxic or anaerobic conditions (Liang et al. 2021). It contains persistent free radicals (PFRs) and defects caused by structural collapse, etc., which can be used to directly oxidize or reduce organic and inorganic pollutants (Yang et al. 2010; Kluepfel et al. 2014; Wu et al. 2017). It also has a high specific surface area, abundant oxygen-containing functional groups, and a large number of 
micropores, which makes biochar has a strong adsorption capacity. It can adsorb organic and inorganic pollutants from the environment (Yang et al. 2015). On the other hand, it can be used as an electron donor to catalyze the activation of hydrogen peroxide and persulfate to produce reactive oxygen species (ROS) to degrade the organic pollutants (Fang et al. 2014, 2015a, b). Therefore, biochar has also been applied in the process of environmental remediation from the agricultural field (Qin et al. 2020; Xie et al. 2015). Phytic acid is widely distributed in nature and is an important nutrient for plant growth and development, accounting for $50-90 \%$ of total plant phosphorus in the plant body as the main storage structure for phosphorus. Phytic acid has a strong chelating ability and rich surface groups. Phytic acid can increase the graphitization degree and yield of modified biochar, and increase the reaction activity of biochar.

Fenton oxidation is a kind of homogeneous catalytic oxidation method widely used in industrial water treatment, and the traditional method of Fenton oxidation uses $\mathrm{Fe}^{2+}$ as an electron donor to catalyze $\mathrm{H}_{2} \mathrm{O}_{2}$, which generates hydroxyl radical $(\cdot \mathrm{OH}, \mathrm{E} 0=1.9-2.7 \mathrm{~V})$ with ultra-high oxidation activity (Guan et al. 2011) and then uses $\cdot \mathrm{OH}$ as the main oxidant to oxidize pollutants. However, there are many malpractices about conventional Fenton oxidation. First, the pH needs to be around 3 (Bokare and Choi 2014). Secondly, $\mathrm{H}_{2} \mathrm{O}_{2}$ has a high price and is difficult to transport and preserve. It was found that persulfate (PS) including peroxymonosulfate (PMS) and peroxydisulfate (PDS) are similar to $\mathrm{H}_{2} \mathrm{O}_{2}$ in that they both produce ROS by breaking the $\mathrm{O}-\mathrm{O}$ bond. Structurally, PS $(\mathrm{E} 0=2.01 \mathrm{~V}$ ) (Yang et al. 2010) is a replacement of two hydrogen atoms of $\mathrm{H}_{2} \mathrm{O}_{2}$ with $\mathrm{SO}_{3}$ groups (Chen et al. 2016). The length of the $\mathrm{O}-\mathrm{O}$ bond of $\mathrm{H}_{2} \mathrm{O}_{2}$ is $1.460 \AA$ (Reints et al. 2000), and the linkage energy is $213.3 \mathrm{~kJ} / \mathrm{Mol}$, while PS has a bond length of 1.497 $\AA$, and the bond energy is $140.0 \mathrm{~kJ} / \mathrm{Mol}$ (Reints et al. 2000). Compared with $\mathrm{H}_{2} \mathrm{O}_{2}$, PS is more stable (Yang et al. 2010). However, PS is also difficult to degrade pollutants efficiently in the absence of external activation (Yang et al. 2015; Liu et al. 2014).

The lower bond energy of PS also leads to its easier catalytic generation of ROS. PS itself has some oxidative properties, but it is not enough to directly oxidize the refractory pollutants and needs external conditions, such as thermal catalysis (Xu et al. 2014; Yang et al. 2016), UV catalysis (Chen et al. 2016), transition metal catalysis (Lau et al. 2007), microwave catalysis (Chou et al. 2015), etc. As an emerging oxidant recently, therefore, PS has attracted increasing attention for wastewater decontamination and in-situ remediation based on advanced oxidation processes (AOPs) (Matzek and Carter 2016). Other studies have found that the sulfidized nanoscale zerovalent iron-persulfate system is effective in situ chemical oxidation (ISCO) agent for the removal of groundwater pollutants. And the s-nzvi-ps system has appreciable efficiency under natural pH (Rayaroth et al. 2020).

Therefore, phytate-modified biochar, a cheap and ecofriendly material is selected to catalyze PS through phytate modification and used to study the oxidative degradation effect on the organic pollutant, ponceau $2 \mathrm{R}$. The mechanism and influencing factors of the reaction process are discussed to clarify the reaction process and obtain the best treatment conditions for practical application.

\section{Materials and methods}

\subsection{Chemicals}

Ponceau $2 \mathrm{R}$ solution was prepared at an initial concentration of $160 \mathrm{mg} / \mathrm{L}$ and used after dilution. The potassium monopersulfate, Ponceau 2R, 5,5-dimethyl L-pyrroline $N$-oxide (DMPO), and 1,1-diphenyl-2-picrylhydrazyl (DPPH) were purchased by Aladdin Co., Ltd. And the purity of the chemical reagents was more than $99 \%$. The sodium hydroxide $(\mathrm{NaOH}$, analytical pure $99 \%)$, muriatic acid $(\mathrm{HCl}, \rho=1.19 \mathrm{~g} /$ $\mathrm{mL}, 36 \%$ ), anhydrous ethanol (Chromatographic purity), and methanol (Chromatographic purity) were purchased from National medicine.

\subsection{Modification of biochar}

Ginkgo biloba rods were taken from the campus of Shaanxi university of science and technology. After removing bark and pith, the retrieved Ginkgo biloba rods were dried in an oven at $80{ }^{\circ} \mathrm{C}$ for $48 \mathrm{~h}$ and then pulverized with a grinder. The particles with uniform particle size were screened with 120-mesh and 200-mesh screens. The particles were placed in a porcelain crucible and then placed in a tubular furnace to begin pyrolysis to prepare biochar. The particles pyrolyzed at $500{ }^{\circ} \mathrm{C}$ in a tubular furnace were named BC500. The biomass particles were mixed with $25 \%$ phytic acid solution according to the solid-liquid ratio of 1:2. After mixing enough, it was put into a muffle furnace with porcelain crumble to start the pyrolysis. The temperature was first increased to $100{ }^{\circ} \mathrm{C}$ at a rate of $10^{\circ} \mathrm{C} / \mathrm{min}$ for $180 \mathrm{~min}$ by passing nitrogen gas and then increased to $300{ }^{\circ} \mathrm{C}, 500{ }^{\circ} \mathrm{C}$, and $700{ }^{\circ} \mathrm{C}$ at a rate of $5{ }^{\circ} \mathrm{C} / \mathrm{min}$ for $180 \mathrm{~min}$. When the temperature was lowered to $70{ }^{\circ} \mathrm{C}$, the biochar was taken out and immediately rinsed with ultra-pure water until the $\mathrm{pH}$ of the biochar was neutral, named PBC300, PBC500 and PBC700.

\subsection{Characterization of biochar}

The surface morphology and element distribution of biochar were observed by field emission scanning electron microscopy (SEM). The specific surface area of biochar 
was measured using a specific surface area analyzer (BET), and the degree of graphitization of biochar was obtained by Raman spectroscopy. Boehm's titration method was used to characterize the content of acidic oxygen-containing functional groups on the surface of biochar. The phosphorus spectrum of biochar was scanned using XPS. The ROS species were measured by Bruker E500 electron paramagnetic resonance (EPR).

\subsection{Degradation of Ponceau 2R by BC-PMS system}

\subsubsection{The experiments of remove of Ponceau 2R}

Removal experiments were performed in $50 \mathrm{~mL}$ brown serum bottles, one treatment was the initial concentrations of $1 \mathrm{~g} / \mathrm{L}, 40 \mathrm{mM}$, and $10 \mathrm{Mm}$ of biochar, ponceau $2 \mathrm{R}$, and PMS, and the other was a simple adsorption experiment without PMS. And $\mathrm{pH}$ was adjusted with $\mathrm{HCl}$ and $\mathrm{NaOH}$ in a total reaction volume of $20 \mathrm{~mL}$. The experiments were carried out at $25{ }^{\circ} \mathrm{C}$ and $150 \mathrm{rpm}$, and the reaction was terminated by the addition of anhydrous ethanol, followed by filtration through a $0.22 \mu \mathrm{m}$ Poly tetra fluoro ethylene (PTFE) membrane. The filtrate was collected and the concentration of residual Ponceau $2 \mathrm{R}$ was determined by liquid mass spectrometry (LC-MS). In this study, we used the C/ $\mathrm{C}_{0}$ to express an approximate degradation rate equal to the total removal rate (with PMS) minus simple adsorption rate in the treatment experiment (without PMS).

\subsubsection{Analysis of the influencing factors of degradation}

BC500, PBC300, PBC500, and PBC700 were added to Ponceau $2 \mathrm{R}$ solution, and then the $\mathrm{pH}$ was adjusted to 3,7 , and 11 using $0.1 \mathrm{M} \mathrm{NaOH}$ solution and $0.1 \mathrm{M} \mathrm{HCl}$ solution, and in the next, PMS was added, and the reaction was started at $150 \mathrm{rpm}, 25^{\circ} \mathrm{C}$ to study the effect of $\mathrm{pH}$.

The configured BC-PMS-Ponceau 2R solution was adjusted to $\mathrm{pH} 7$ and then placed in a shaker at $20{ }^{\circ} \mathrm{C}$, $25^{\circ} \mathrm{C}$, and $30^{\circ} \mathrm{C}$ at $150 \mathrm{rpm}$ for the reaction degradation experiments to study the effect of temperature. And then the graphs were plotted based on the obtained data using origin software.

\subsubsection{Identification of degradation intermediates and pathways}

The degradation intermediates were analyzed by LC-MS (Bao et al. 2021) with an Ultimate 3000 UHPLC-Q Exactive system (Thermo Scientific, the US). The mode of the electrospray ionization (ESI) source was positive and negative, and the spraying voltage was $4 \mathrm{kV}$ and $3.8 \mathrm{kV}$, respectively. The drying gas flow rate was $1.0 \mathrm{~mL} / \mathrm{L}$, and the drying temperature was $350{ }^{\circ} \mathrm{C}$. The degradation intermediates were separated using a C18 column $(100 \mathrm{~mm} \times 2.1 \mathrm{~mm}, 1.7 \mu \mathrm{m}$, Waters, BEH). The column temperature was set at $25^{\circ} \mathrm{C}$, and the injection volume was $10 \mu \mathrm{L}$. Further analysis of the $\mathrm{m} / \mathrm{z}$ and structure of the possible intermediates in the collected data was carried out using MS software.

\subsubsection{Analysis of degradation mechanism}

The ROS capturing agent selected for this experiment was dimethyl pyridine $N$-oxide (DMPO), and $0.16 \mathrm{M}$ DMPO solution was mixed with biochar $(1 \mathrm{~g} / \mathrm{L})$ and PMS $(10 \mathrm{mM})$ to capture hydroxyl radicals under ultra-pure water conditions and singlet oxygen under anhydrous ethanol conditions, and the ROS species produced by $\mathrm{PBC} 300, \mathrm{PBC} 500$, $\mathrm{PBC} 700$, and $\mathrm{BC} 500$ during activation of PMS were measured by EPR.

\section{Results and discussion}

\subsection{Characterization of materials}

The morphology of Ginkgo biloba biochar was checked by SEM, and the results are shown in Fig. 1. Comparing Fig. 1a, b, and Fig. 1c, it can be found that the biochar with phytic acid is more likely to form a honeycomb shape during the pyrolysis process, and the morphology is neater. But BC500 is irregularly columnar with more surface folds and no pores visible. PBC300 is irregularly columnar with rough side surfaces, uneven and honeycomb-like at the crosssection, and the cross-section contains a large number of small pores of about $10 \mu \mathrm{m}$ in diameter. With the increase of pyrolysis temperature, it gradually formed a regular and smooth column, and the cross-section showed a large number of small pores. PBC500 section had small pores in the range of about 10-15 $\mu \mathrm{m}$, and the inner surface of small pores was very smooth, and the inner surface also had a large number of pores about $2-3 \mu \mathrm{m}$ in diameter. PBC700 section had pores in the range of 5-30 $\mu \mathrm{m}$ in diameter, and the inner wall of the section also contained a large number of transversely distributed small pores with a pore diameter of about $200 \mathrm{~nm}$.

The phytic acid already affected the pyrolysis of biochar at $300{ }^{\circ} \mathrm{C}$. It indicated that the single layer of carbon on the surface of the phytate modified biochar started to peel off when the temperature increased from 300 to $500{ }^{\circ} \mathrm{C}$, and the comparison of the pore diameters of $\mathrm{PBC} 300$ and PBC500 sections showed that the carbon layer on the inner surface of the small pores of biochar also started to shed at the pyrolysis temperature of $500{ }^{\circ} \mathrm{C}$, so the surface gradually became smooth, and the pore diameter became larger. When the temperature continued to rise to $700{ }^{\circ} \mathrm{C}$, all the carbon layers 


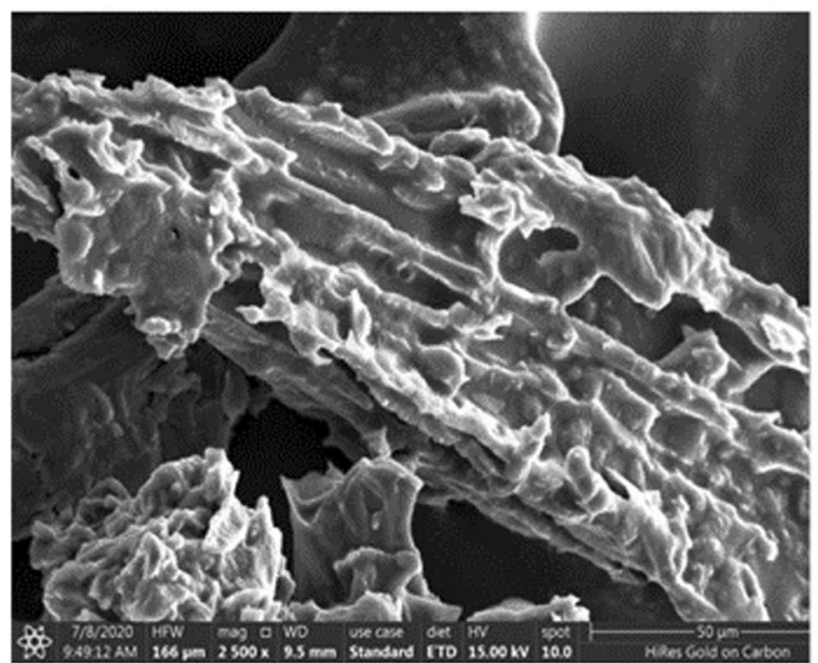

(a)

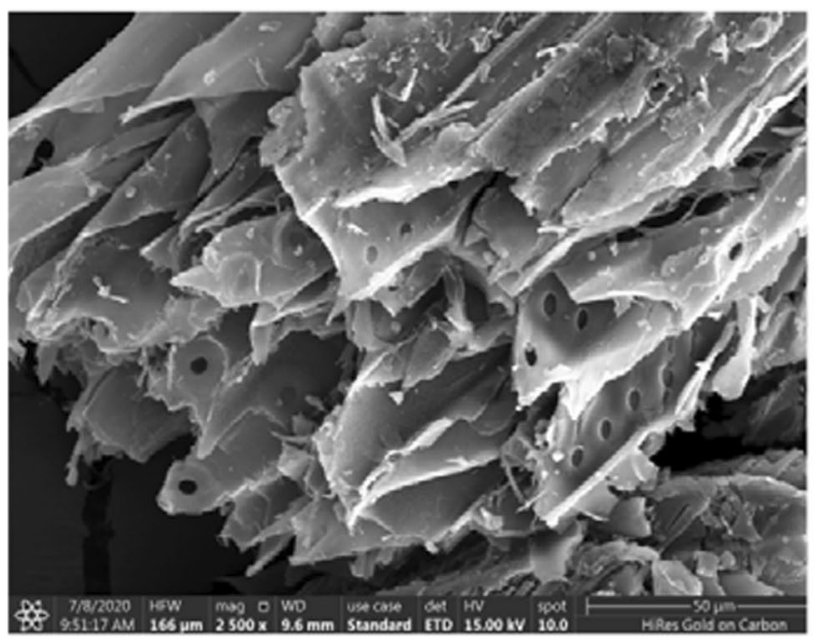

(c)

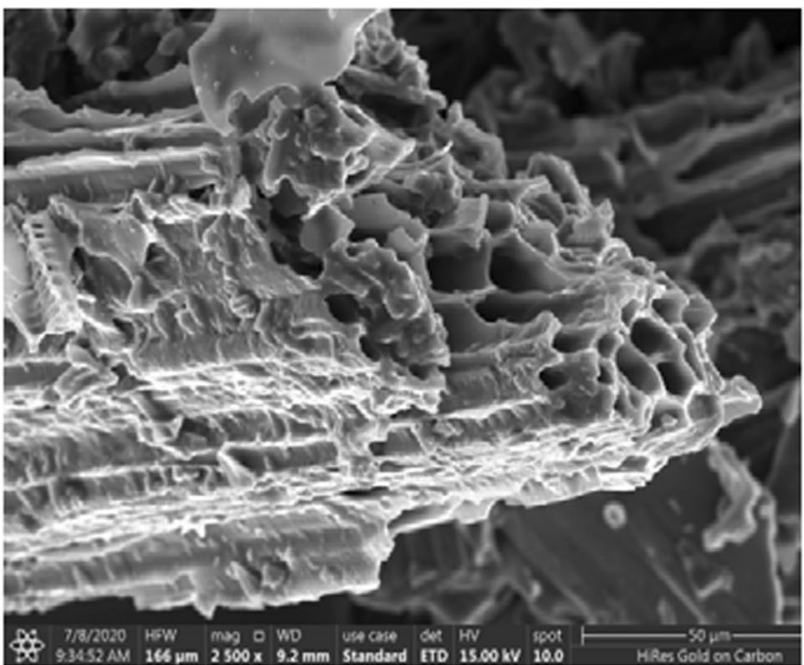

(b)

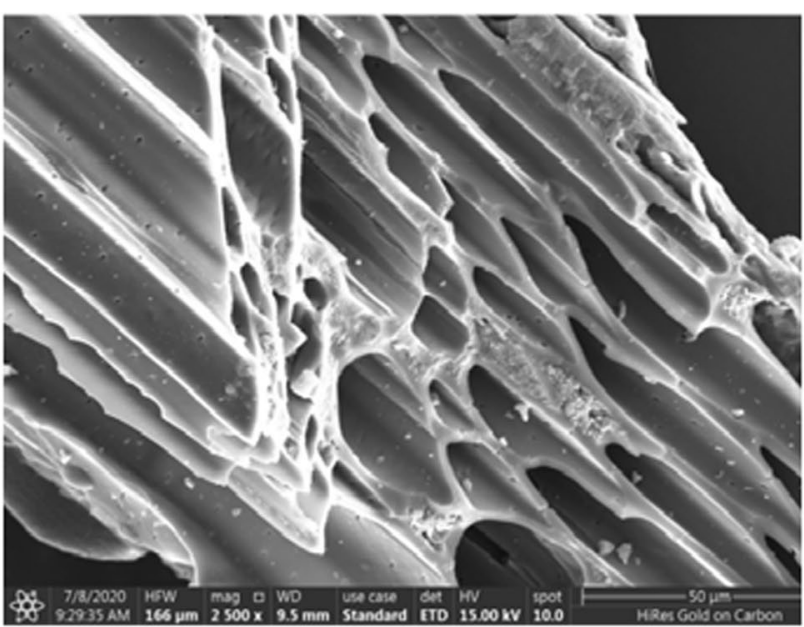

(d)

Fig. 1 Electron microscope scans of biochars (a BC500; b PBC300; c PBC500; d PBC700)

originally contained in the surface at $500{ }^{\circ} \mathrm{C}$ shed, and the surface became very smooth.

In this study, the phosphorus spectrum of biochar was scanned using XPS and the P2p track was divided into 3 peaks (Fig. 2). The peak $\mathrm{P} 1$ at a binding energy intensity of $136.8 \mathrm{eV}$ is $-\mathrm{O}-\mathrm{PO}_{3} /-\mathrm{P}_{2} \mathrm{O}_{6}$, the peak $\mathrm{P} 2$ at a binding energy intensity of $134.12 \mathrm{eV}$ is $\mathrm{O}-\mathrm{P} / \mathrm{C}-\mathrm{PO}_{3}$, and the peak $\mathrm{P} 3$ at a binding energy intensity of $131.8 \mathrm{eV}$ is $\mathrm{C}-\mathrm{P}$ (Valero-Romero et al. 2017). The intensity of the P1 peak was the highest in PBC500 and changed very significantly, which indicated that more metaphosphoric acid attached to oxygen atoms was formed in PBC500. And the compounds -O- $-\mathrm{PO}_{3} /-\mathrm{P}_{2} \mathrm{O}_{6}$ and $\mathrm{O}-\mathrm{P} / \mathrm{C}-\mathrm{PO}_{3}$ underwent a mutual transformation during the pyrolysis process. The changing patterns of $\mathrm{P} 1, \mathrm{P} 2$, and $\mathrm{P} 3$ peaks indicated that the chemical state of the $\mathrm{P}$ atom changes continuously during the pyrolysis process, with the
$\mathrm{C}-\mathrm{PO}_{3}$ chemical bond first changing to $\mathrm{C}-\mathrm{O}-\mathrm{PO}_{3}$ and then to $\mathrm{C}-\mathrm{PO}_{3}$ and $\mathrm{C}-\mathrm{P}$. C-P-O bonds are not very stable at high temperatures (Mckee et al. 1984), and C-O-P bonds will be more stable than $\mathrm{C}-\mathrm{P}-\mathrm{O}$ bonds under high-temperature conditions (Lee and Radovic 2003). And phosphate is often attached to the surface of biochar through C-O-P bonds (Puziy et al. 2008; Lee and Radovic 2003).

As is shown in Fig. 3. two characteristic peaks appear in the Raman spectrum around wavelengths $1329 \mathrm{~cm}^{-1}$ and $1583 \mathrm{~cm}^{-1}$, D peak appearing around $1300 \mathrm{~cm}^{-1}$, and $\mathrm{G}$ peak appearing around $1580 \mathrm{~cm}^{-1}$ (Li et al. 2021). So, they are corresponding to the $\mathrm{D}$ and $\mathrm{G}$ peaks of graphite, the $\mathrm{D}$ peak represents the defect peak, which is caused by the low symmetry or irregularity of the carbon material and corresponds to doping, defects, wobbly bonds, and bent graphite layers in the graphite structure. The $\mathrm{G}$ peak represents the graphite 


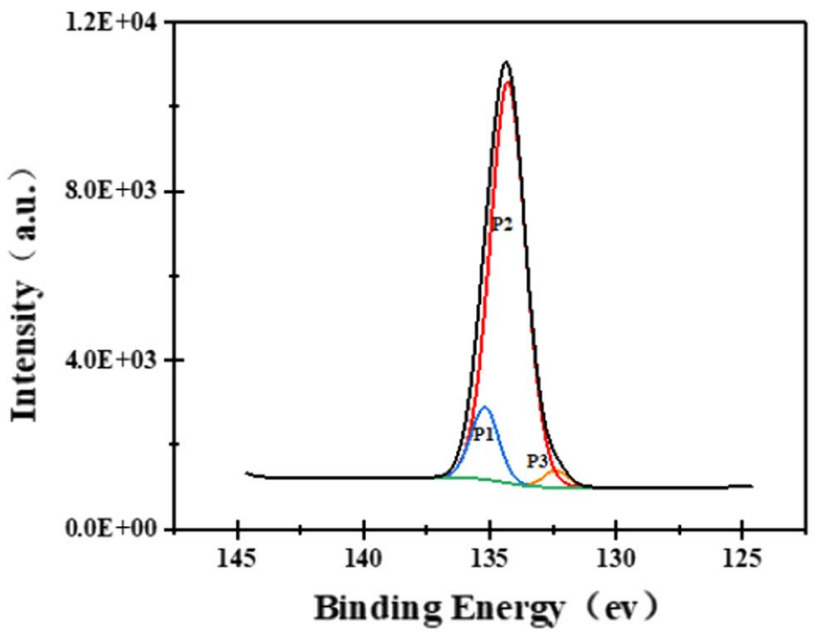

(a)

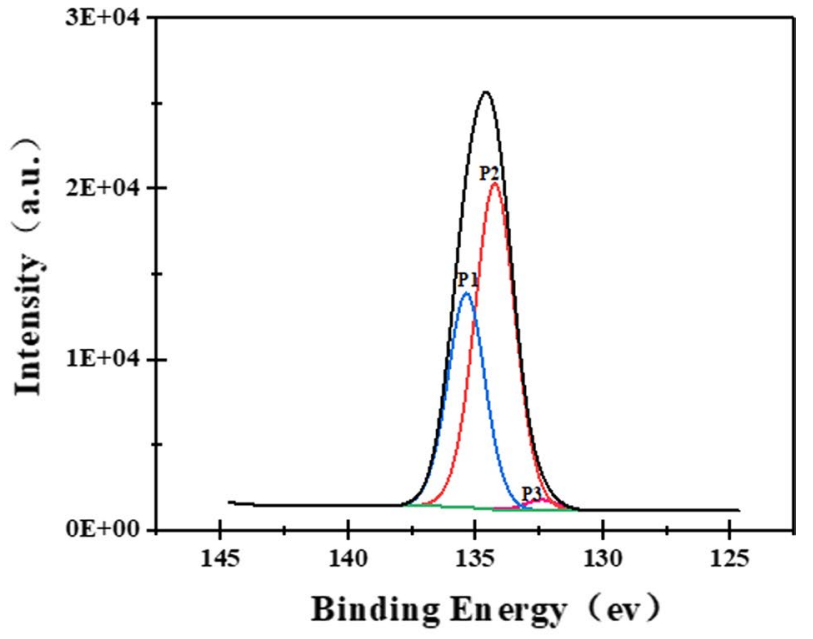

(b)

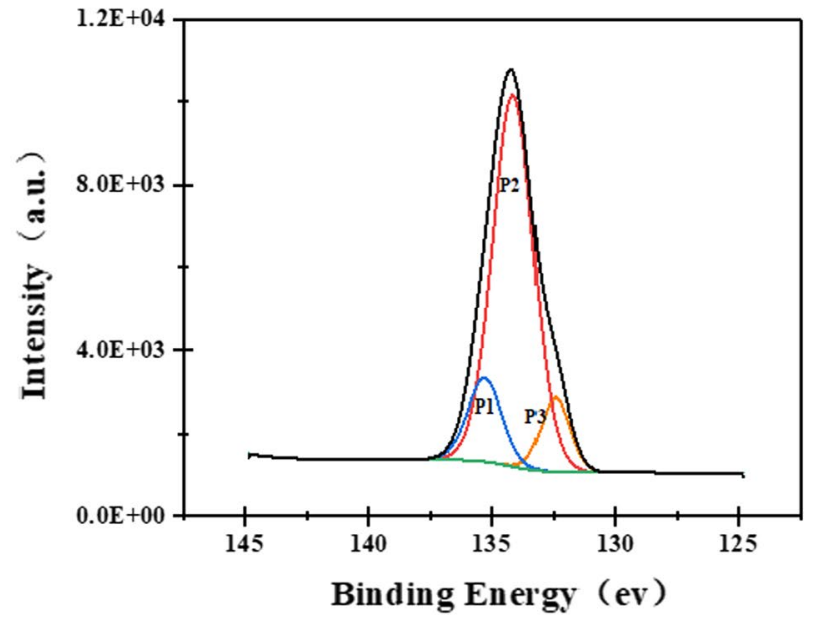

(c)

Fig. 2 P2p orbital peaks of PBC300, PBC500 and PBC700 (a PBC300; b PBC500; c PBC700)

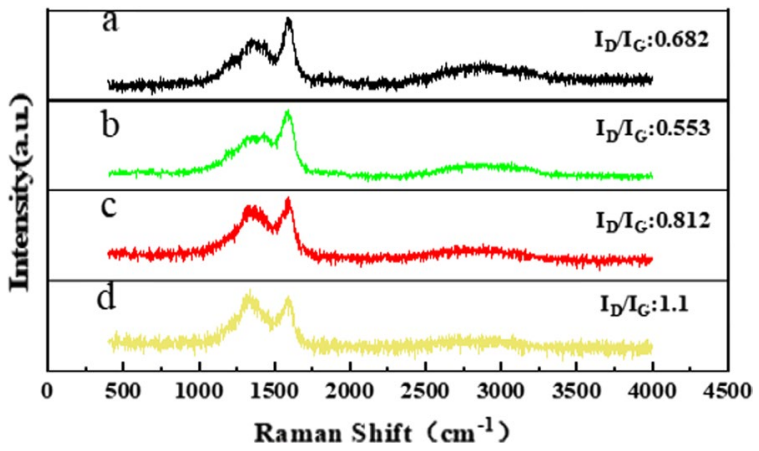

Fig. 3 Raman spectra of biochars (a BC500; b PBC300; c PBC500; d PBC700)

peak, whose peak reflects the degree of graphitization and is caused by the $\mathrm{sp} 2$ vibration of the graphite hexagonal structure. Raman plots of all four biochars showed distinct first-order peaks at $1340 \mathrm{~cm}^{-1}$ (D-Band) and $1590 \mathrm{~cm}^{-1}$ (G-Band). The intensity ratio of D-peak to G-peak reflects the orderliness of biochar. The ID/IG ratios of PBC300, PBC500, and PBC700 were 0.553, 0.812, and 1.1, respectively. It can be seen that the orderliness of biochar increased with the increase of pyrolysis temperature. PBC500 was more ordered than BC500. The possible reasons are as follows: firstly, the catalytic dehydration of acids; secondly, the enhancement of aromatization of carbon atoms; thirdly, the increase of hole formation rate; exceeded. The ID/IG ratio of PBC700 exceeds 1.04, so there may be defective activation of PBC700 during catalytic PMS.

\subsection{Effect of solution pH and temperature on the degradation}

The results of the influence of $\mathrm{pH}$ on degradation are shown in Fig. 4. The ability of BC500 to catalyze PMS degradation 

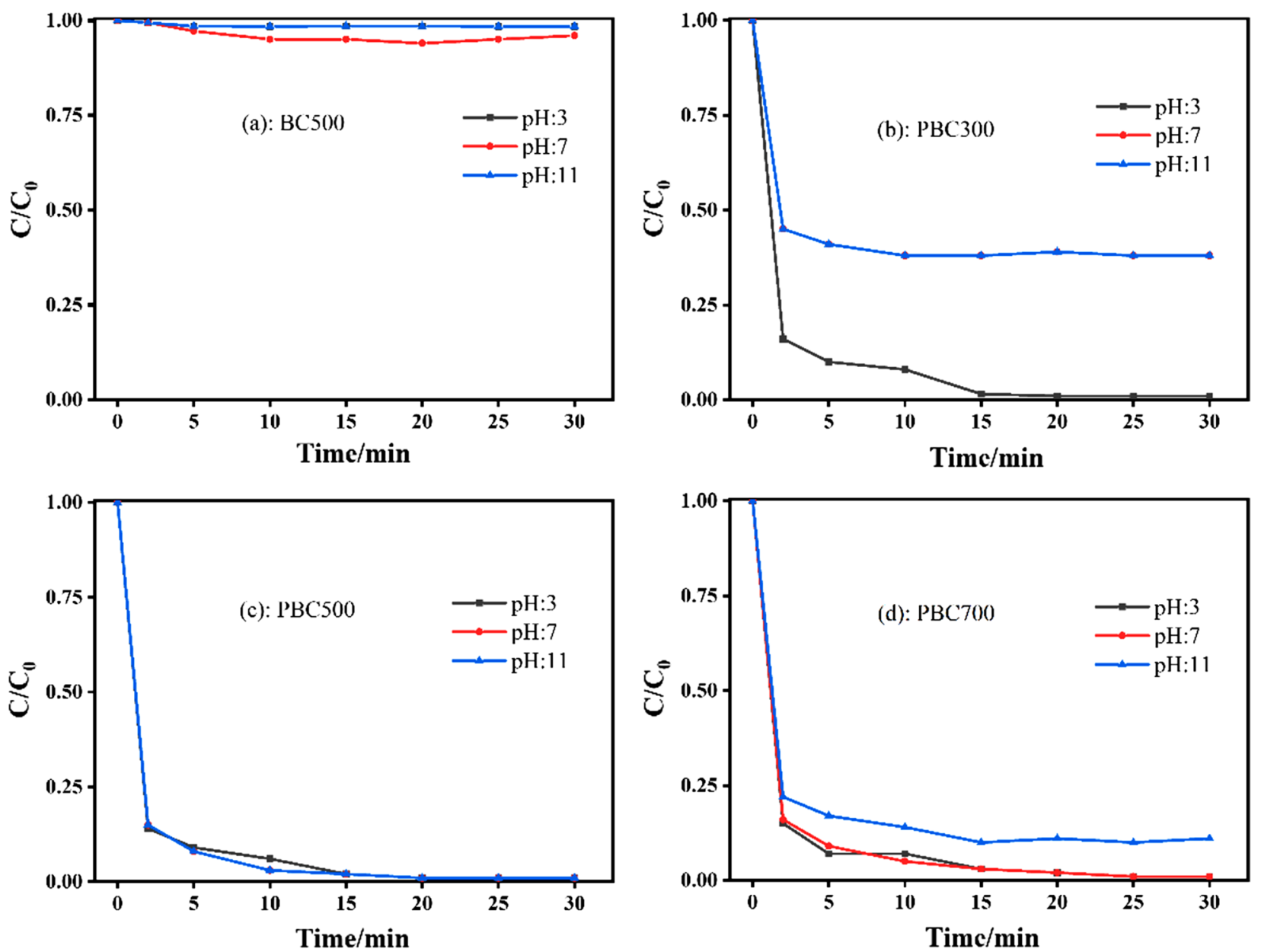

Fig. 4 Effect of pH on degradation of Ponceau 2R

of Ponceau 2R did not change significantly at different $\mathrm{pH}$ ranges, and the reaction equilibrium was reached at $10 \mathrm{~min}$, and at most 5\% of Ponceau 2R could be degraded. The possible reason was that the insufficient active sites exposed on the surface of BC500 could catalyze PMS. PBC300 had the best catalytic capacity at acidic $\mathrm{pH}$ and could remove $90 \%$ of Ponceau 2R from the solution at a reaction time of 5 min. The maximum removal of Ponceau 2R, 99\%, was reached at a reaction time of 15-20 min and the maximum removal of Ponceau $2 \mathrm{R}$ by PBC300 under both neutral and alkaline conditions was $62 \%$. The catalytic degradation ability of PBC500 was not significantly affected by $\mathrm{pH}$, and it could efficiently treat Ponceau 2R under acidic, neutral, and alkaline conditions, achieving 99\% degradation and removal in 15-20 min of reaction time. As the temperature increases, the lignin fraction within the biomass continues to fracture, enhancing the richness of catalytic active sites on the surface of PBC500 (Meng et al. 2020). The catalytic ability of $\mathrm{PBC} 700$ was stronger at $\mathrm{pH} 3$ and 7 but weaker at $\mathrm{pH} 11$. More than $99 \%$ of Ponceau $2 \mathrm{R}$ was removed at $\mathrm{pH} 3$ and 7 within $20-25 \mathrm{~min}$, while the maximum removal rate of PBC700 was $90 \%$ at $\mathrm{pH} 11$ at $10-15 \mathrm{~min}$. It indicated that for PBC700 acidic and neutral conditions did not affect the ability of biochar to catalyze PMS to produce ROS, but the ability of biochar to produce ROS became significantly weaker under alkaline conditions.

As indicated in Fig. 5, the ability of BC500 to catalyze the degradation of Ponceau $2 \mathrm{R}$ by PMS was not significantly affected by the change of temperature, and it can be inferred from the changing trend that BC500 had almost no ability to catalyze the degradation of Ponceau $2 \mathrm{R}$ by PMS, and it mainly relied on the adsorption to remove the Ponceau 2R from the solution. The ability of PBC300 to catalyze PMS degradation of Ponceau $2 \mathrm{R}$ was weaker at low temperature and enchanted at $25^{\circ} \mathrm{C}$ and $30{ }^{\circ} \mathrm{C}$. At $25{ }^{\circ} \mathrm{C}$ and $30{ }^{\circ} \mathrm{C}, 57 \%$ of Ponceau $2 \mathrm{R}$ can be removed in $2 \mathrm{~min}$ and reached the equilibrium in 5-10 $\mathrm{min}$, and the maximum removal of Ponceau 2R was $62 \%$. This indicates that $\mathrm{PBC} 300$ needs a certain temperature in catalytic PMS degradation of Ponceau 2R, and the catalytic ability decreases below $25{ }^{\circ} \mathrm{C}$. The ability of PBC500 and PBC700 to catalyze PMS degradation of Ponceau 2R was 

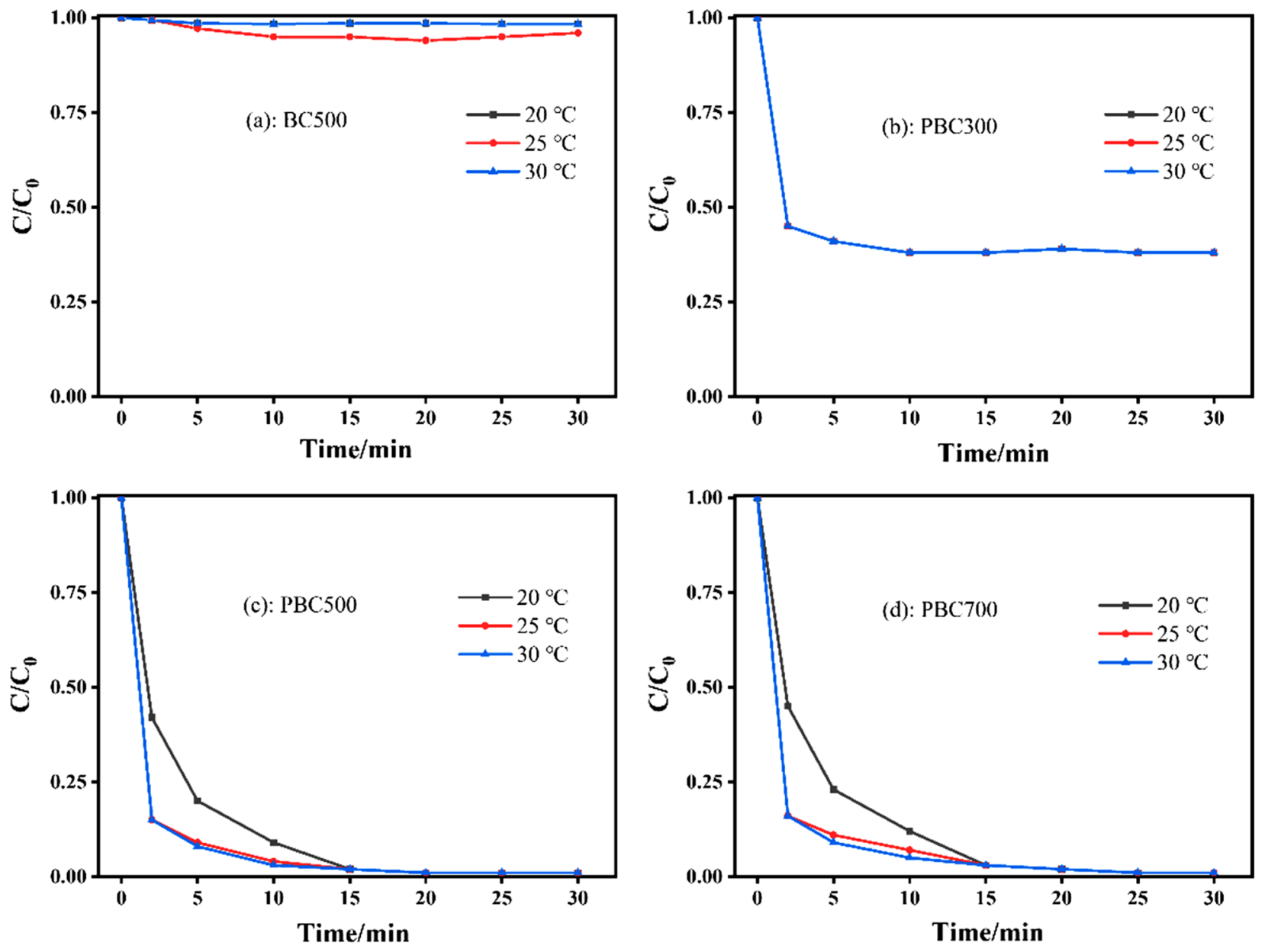

Fig. 5 Effect of temperature on degradation of Ponceau 2R

affected by temperature in a similar trend. The reaction speed was slower at $20^{\circ} \mathrm{C}$, and the reaction equilibrated at $10-15 \mathrm{~min}$ to reach the maximum degradation, and the reaction at $25{ }^{\circ} \mathrm{C}$ and $30{ }^{\circ} \mathrm{C}$ reached the maximum degradation at 5-10 min. It shows that low temperature is also unfavorable for PBC catalyzed PMS degradation of Ponceau 2R. And it is consistent with the conclusion that persulfate has different activation effects at different temperatures from other studies (Nie et al. 2014).

In summary, it is not yet clear that the reason for the difference in $\mathrm{pH}$ on $\mathrm{PBC} 300$ and $\mathrm{PBC} 700$. The oxidation activity of PBC500 was stronger than that of PBC300 under all conditions, which showed that the increase of lysis temperature did help to increase the metaphosphoric acid on the surface of biochar and increase the active sites. However, the continual increase of temperature $\left(700{ }^{\circ} \mathrm{C}\right)$ resulted in increasing aromatization of carbon atoms, shedding of carbon layers and creation of structural defects, which may facilitate electron transfer.

\subsection{Mechanism of degradation of environmental Ponceau 2R by BC-PMS system}

To further investigate the main degradation pathway of Ponceau $2 \mathrm{R}$ in the BC-PMS system, the degradation intermediates were analyzed by LC-MS, and the results are shown in Fig. 6. The results showed that $\mathrm{C}_{6} \mathrm{H}_{6} \mathrm{O}_{2}$ and $\mathrm{C}_{8} \mathrm{H}_{8} \mathrm{O}$ were the main degradation products. The mass spectra of Ponceau $2 \mathrm{R}$ at $15 \mathrm{~min}$ (Fig. 7) indicated that the main proton molecules $\mathrm{m} / \mathrm{z}$ were 83.0809 and 338.3409 and the relative molecular weight was 84 ; the molecular formula was presumed to be $\mathrm{C}_{5} \mathrm{H}_{8} \mathrm{O}$. The possible degradation pathways of Ponceau 2R are shown in Fig. 8.

The results of the content of acidic oxygen-containing functional groups are shown in Table 1, and it can be found that BC500 and PBC500 have a similar distribution of surface oxygen functional groups, however, according to Figs. 3 and 4, there is a big difference in the ability of BC500 and PBC500 to catalyze PMS degradation of Ponceau 2R. 

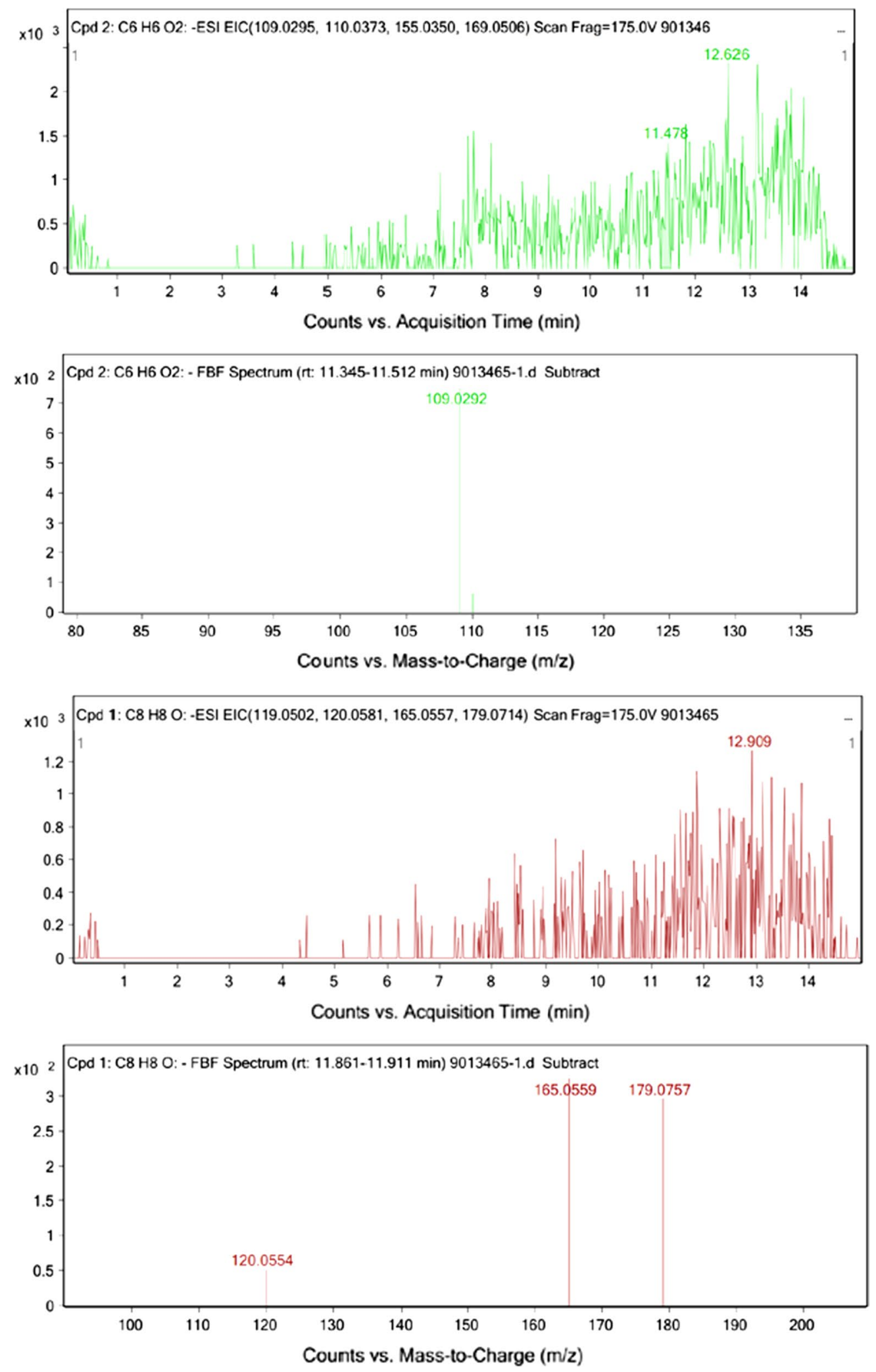

Fig. 6 The chromatogram and mass spectrum of degradation intermediates of Ponceau 2R 


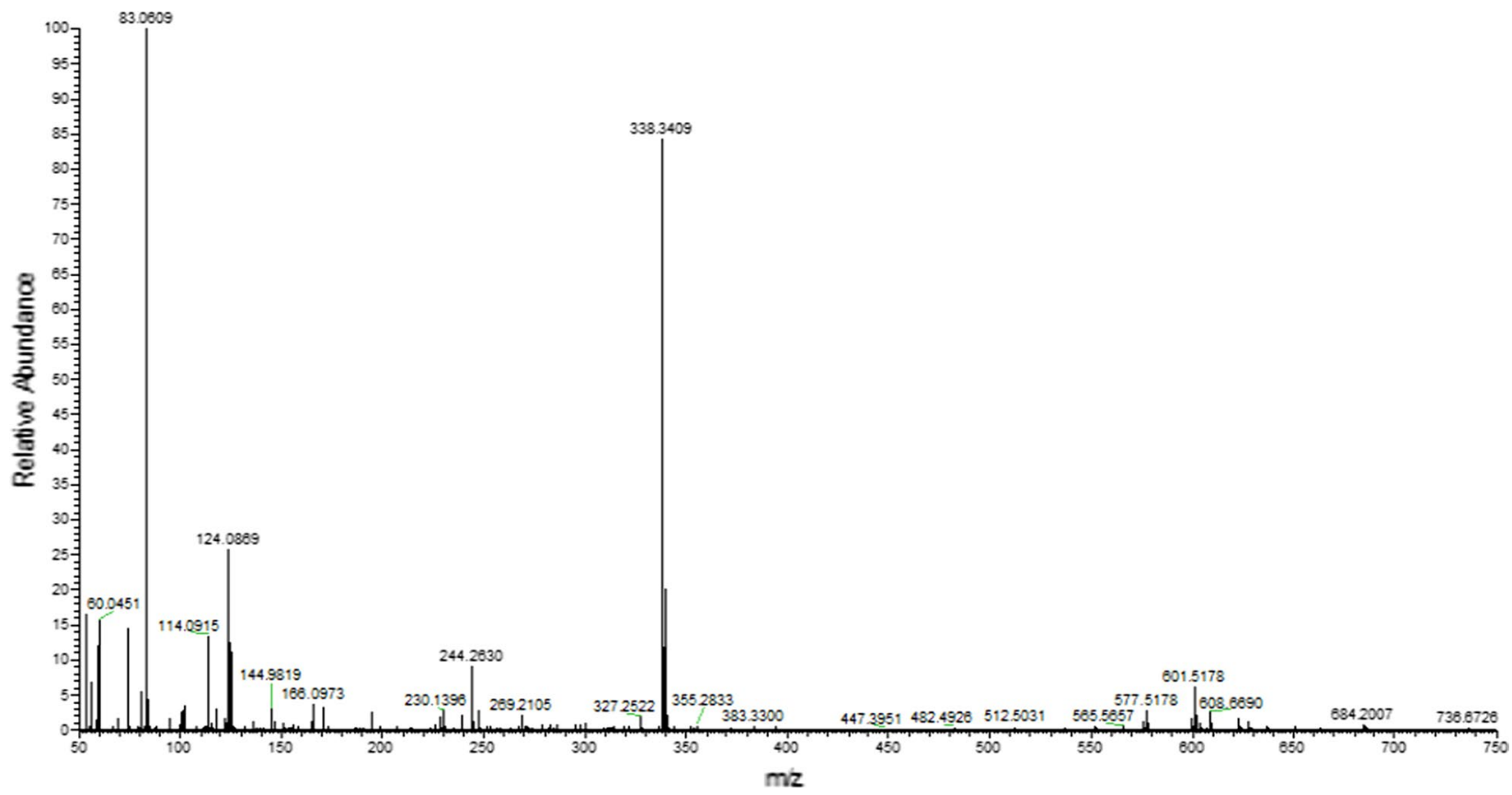

Fig. 7 The mass spectrum of Ponceau 2R at $15 \mathrm{~min}$

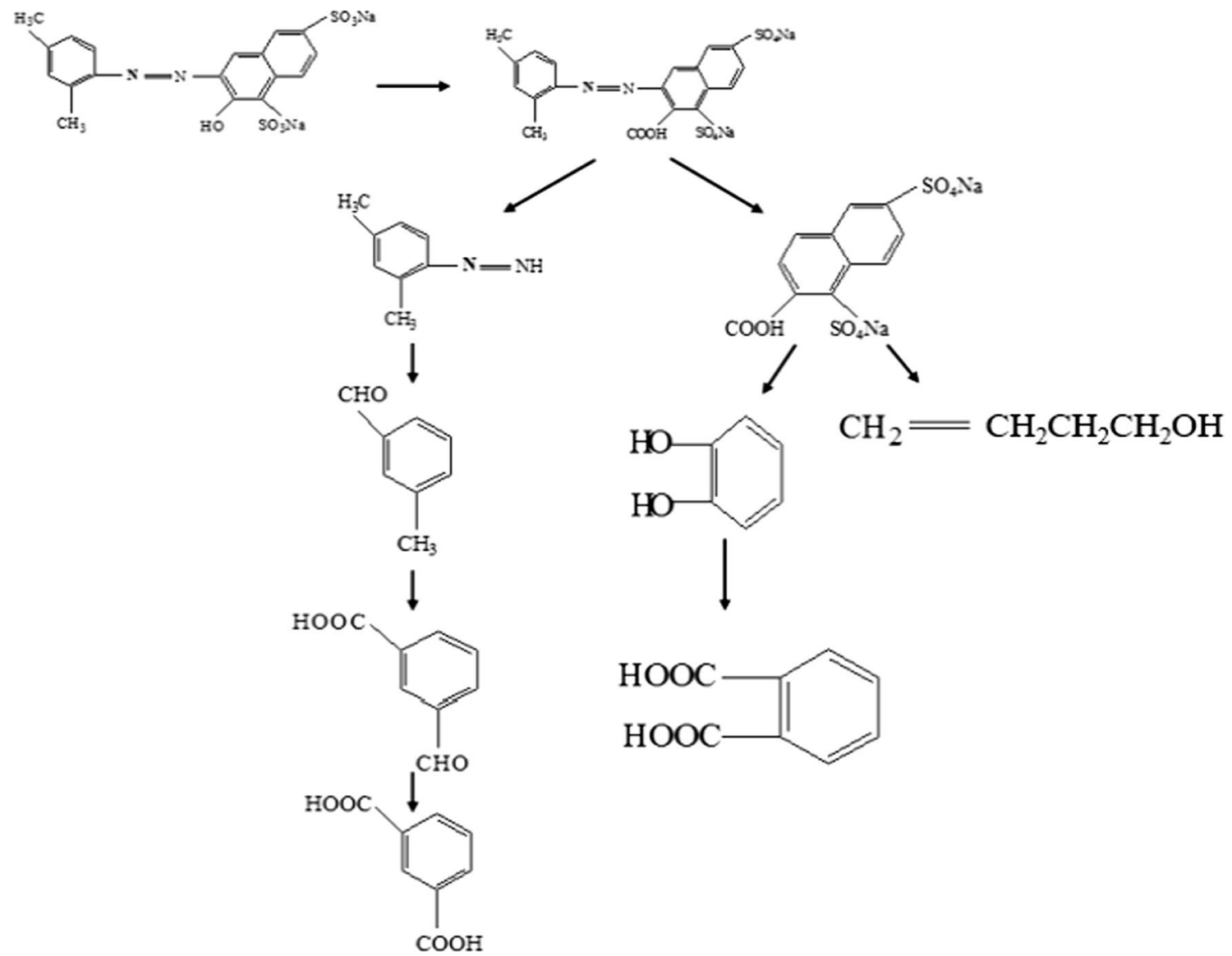

Fig. 8 Degradation pathway of Ponceau 2R 
Table 1 Determination of surface oxygenated functional groups of biochars

\begin{tabular}{llllll}
\hline Sample & $\begin{array}{l}\text { Carboxyl } \\
\text { group } \\
(\mathrm{mmol} / \mathrm{g})\end{array}$ & $\begin{array}{l}\text { Lactone group } \\
(\mathrm{mmol} / \mathrm{g})\end{array}$ & $\begin{array}{l}\text { Hydroxyl } \\
\text { group } \\
(\mathrm{mmol} / \mathrm{g})\end{array}$ & $\begin{array}{l}\text { Carbonyl } \\
\text { group } \\
(\mathrm{mmol} / \mathrm{g})\end{array}$ & $\begin{array}{l}\text { Total oxygen-containing } \\
\text { functional groups }(\mathrm{mmol} / \mathrm{g})\end{array}$ \\
\hline BC500 & 0.1375 & 0.2001 & 0.06784 & 0.25443 & 0.65988 \\
PBC300 & 0.0985 & 0.16845 & 0.0412 & 0.2356 & 0.54375 \\
PBC500 & 0.1364 & 0.19652 & 0.0689 & 0.2548 & 0.65662 \\
PBC700 & 0.0598 & 0.13548 & 0.0245 & 0.1569 & 0.37659 \\
\hline
\end{tabular}

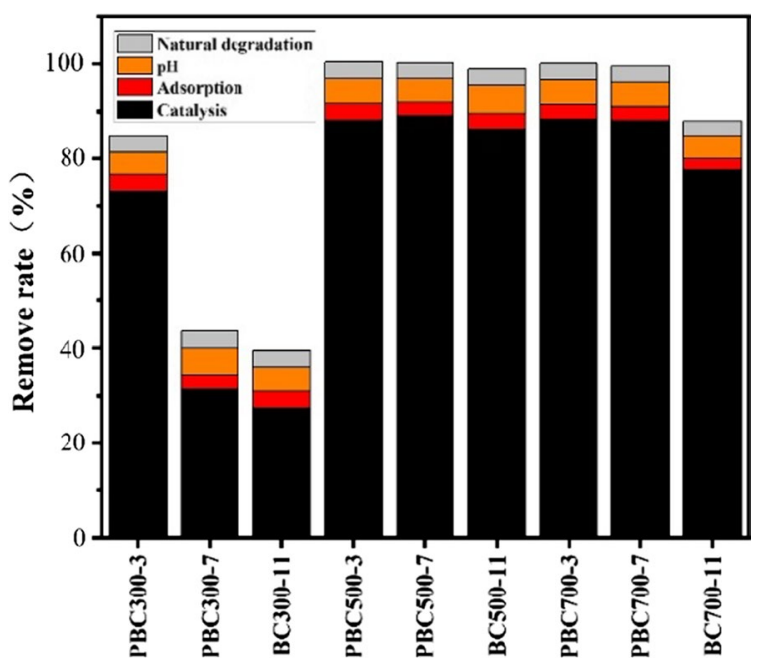

Fig. 9 The degradation of Ponceau 2R by biochar is affected by natural degradation, $\mathrm{pH}$, adsorption, and catalysis

BC500 showed almost no degradation ability for Ponceau 2R, while PBC500 degraded 99\% of Ponceau 2R in $10 \mathrm{~min}$. PBC700, which had the least surface oxygen functional groups, had higher degradation capacity than PBC300 and PBC500, which had higher surface oxygen abundance and it can be inferred that the surface oxygen functional groups are not involved in the catalytic PMS degradation of Ponceau $2 \mathrm{R}$.

To further investigate the main degradation factors of the BC-PMS system in the degradation of Ponceau 2R, the amount of Ponceau 2R removed by PMS under the action of $\mathrm{pH}$, and the amount of adsorption and removal by biochar were analyzed. The role of various factors in the degradation of Ponceau 2R by PBC300, PBC 500, and PBC 700 is shown in Fig. 9. It can be seen that the degradation of Ponceau $2 \mathrm{R}$ was less affected by $\mathrm{pH}$; the adsorption removal of biochar was not the main factor leading to the removal of Ponceau 2R. PMS degraded more Ponceau 2R under the action of modified biochar, which showd that the degradation of Ponceau 2R catalyzed by phytate-modified biochar was the main degradation factor. PBC 300 can efficiently catalyze PMS only under acidic conditions, but not under neutral and alkaline conditions. PBC 500 and PBC 700 can efficiently catalyze PMS not only under acidic conditions but also under neutral and alkaline conditions. This may be because there were enough active sites on the surfaces of PBC500 and PBC700 to catalyze PMS. At pH 3, 7, and 11 , sufficient ROS can be produced to degrade Ponceau 2R. However, there were not enough active sites on the surface of PBC300. The ability to catalyze the production of ROS was inhibited under neutral and alkaline conditions, which cannot effectively degrade Ponceau 2R.

In this experiment, ROS were captured in three biocharcatalyzed PMS processes. It was characterized by the capture signal of EPR and quantified by using free radical standards. As shown in Fig. 10; Table 2, PBC500 produced the highest concentration of ROS in the catalytic PMS process and the type of ROS was hydroxyl radical; PBC700 produced ROS as singlet oxygen; PBC300 produced ROS as hydroxyl radical in the catalytic process and the lowest concentration. This explains the superior catalytic performance of PBC500 compared to the others. The Raman characterization of PBC700 showed that the ID/IG value of PBC700 was 1.1 (>0.85), indicating that $\mathrm{PBC} 700$ can also generate electron transfer from defects in the structure and catalyze PMS finally.

To further infer whether the catalysts were catalyzed by persistent radicals, the three phytate-modified biochars were treated with anhydrous ethanol for $5 \mathrm{~h}$ to quench the persistent radicals in the biochars, and the changes in the catalytic capacity of PBC300, PBC500, and PBC700 were observed. The EPR spectra of three biochars after $5 \mathrm{~h}$ of treatment with anhydrous ethanol are shown in Fig. 11. It can be seen that the persistent radicals in $\mathrm{PBC} 300$ and PBC500 were completely burst after $5 \mathrm{~h}$ of treatment with ethanol, and the EPR signal can still be detected in PBC700, which can be considered as a structural defect in the biochar during pyrolysis. According to Fig. 12, there existed differences in the adsorption capacity of ethanol-treated PBC300, PBC500, and PBC700 and untreated biochars on the catalytic process of PMS. The adsorption capacity of the ethanol-treated biochar was higher than that of the untreated biochar, but the adsorption capacity was not very high compared with the total amount removed. The removal of Ponceau 2R mainly depended on the biochar to catalyze PMS to generate ROS for degradation. The removal amount of biochar treated with 


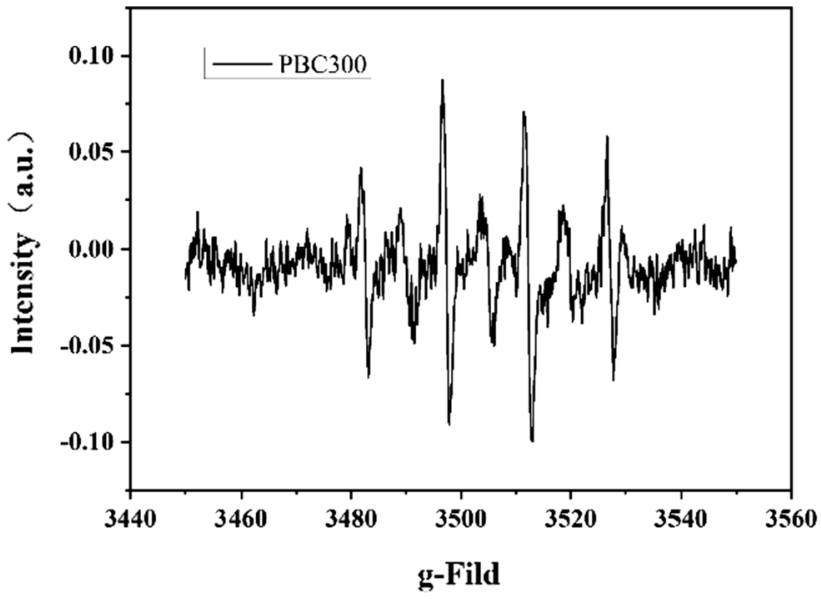

(a)

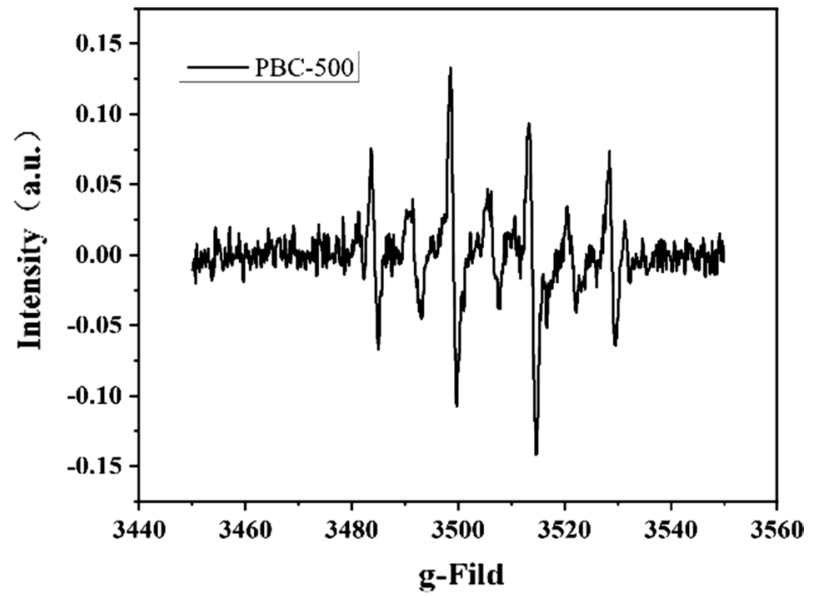

(b)

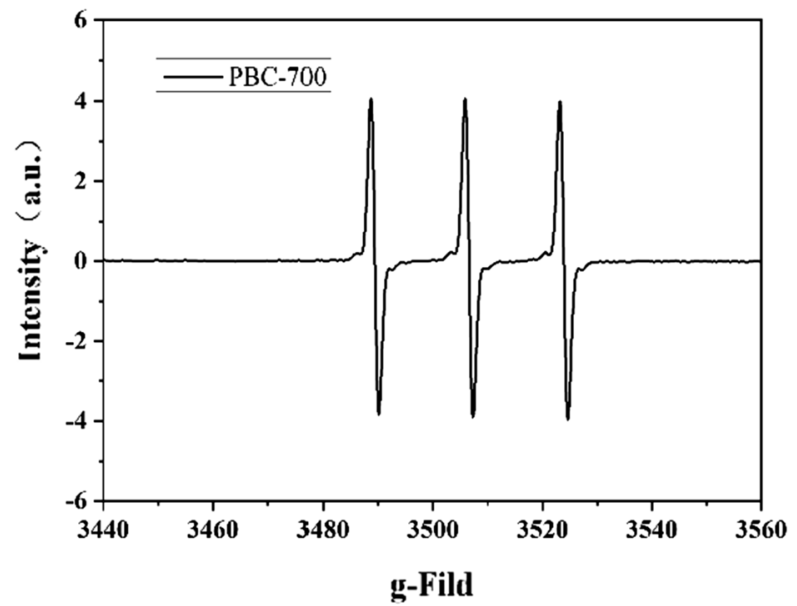

(c)

Fig. 10 ROS signal generated by PBC300, PBC500 and PBC700 in PS catalysis

Table 2 Concentration, type and peak width of ROS produced by PBC300, PBC500 and PBC700 in PMS

\begin{tabular}{llllc}
\hline & Double intergration & $\mathrm{N}\left(\right.$ spins $\left.\times 10^{21} / \mathrm{L}\right)$ & Type & Peak width \\
\hline PBC300 & 12.1546 & 1.1685 & $\cdot \mathrm{OH}$ & 47 \\
PBC500 & 14.5625 & 1.4912 & $\cdot \mathrm{OH}$ & 46 \\
PBC700 & 14.2781 & 1.4531 & Singlet oxygen & 192 \\
\hline
\end{tabular}

ethanol did not change significantly compared with that of biochar not treated with ethanol, indicating that the persistent radicals of biochar did not participate in the catalytic process of PMS. Therefore, it can be speculated that one of the catalytic pathways of PBC700 was caused by a defect in the structure.

In summary, PBC300, PBC500, and PBC700 may have metaphosphoric acid attached to oxygen atoms and metaphosphoric acid attached in a bridging manner on the surface of biochar catalyzed the production of hydroxyl radicals from PMS, and PBC700 may also catalyze the production of singlet oxygen from PMS through its structural defects, and singlet oxygen was the main catalytic product of PBC700.

\section{Conclusions}

1. The surface properties as well as the internal persistent radical content of the phytate modified biochar changed significantly. The ability of modified biochar to treat Ponceau 2R was substantially improved compared with unmodified biochar. 


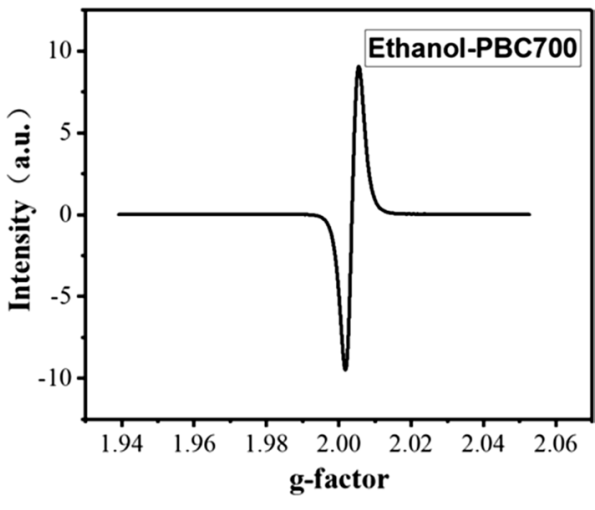

Fig. 11 EPR spectrum of PBC700 after ethanol treatment

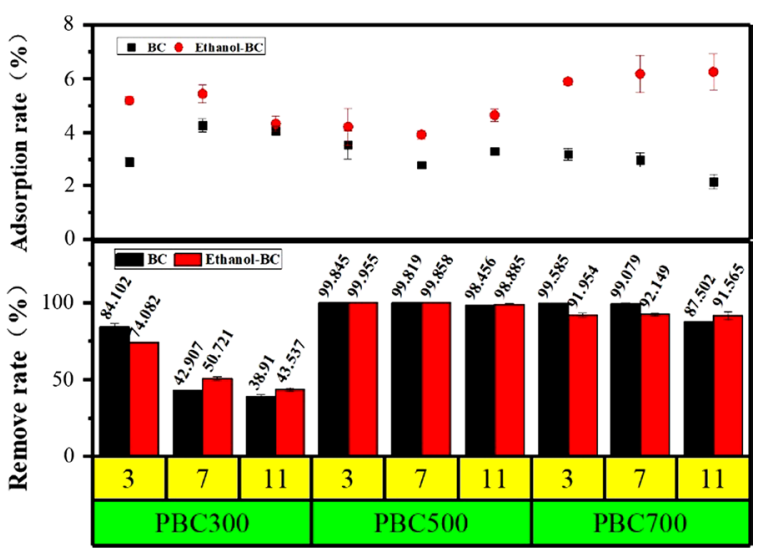

Fig. 12 Removal of Ponceau 2R by PBC300, PBC500, and PBC700 before and after ethanol treatment

2. The effect of $\mathrm{pH}$ on the degradation ability of phytate modified biochar depended on the pyrolysis temperature of biochar, but it had no obvious effect on non-modified biochar. The effect of temperature on the degradation effect was similar to that of $\mathrm{pH}$.

3. The possible reason for phytate modified biochar to catalyze PMS was the metaphosphoric acid on the surface of biochar, and the oxygen-containing functional groups on the surface of biochar with persistent free radicals did not catalyze PMS directly.

Acknowledgements The study was partially supported by the 13th Five-Year key research program of China (2017YFB0308303), Key Research \& Development programs of Shaanxi Province (2018SF363), and Key Research \& Development programs of Weiyang District, Xian (202043).

Authors' contributions All authors contributed to the research conception and design. Material preparation, data collection, and analysis were performed by TC, ZL, and TW. The first draft of the manuscript was written by $\mathrm{LH}$ and all authors commented on previous versions of the manuscript. All authors read and approved the final manuscript.
Funding The study was partially supported by: the 13th Five-Year key research program of China (2017YFB0308303). Key Research \& Development programs of Shaanxi Province (2018SF363). Key Research \& Development programs of Weiyang District, Xian (202043).

Availability of data and materials The datasets generated during the current study are available from the corresponding author on reasonable request.

Code availability Not applicable.

\section{Declarations}

Ethical approval There are no ethics involved in the study, so no ethical approval is required.

Conflict of interest All authors certify that they have no affiliations with or involvement in any organization or entity with any financial interest or non-financial interest in the subject matter or materials discussed in this manuscript.

Open Access This article is licensed under a Creative Commons Attribution 4.0 International License, which permits use, sharing, adaptation, distribution and reproduction in any medium or format, as long as you give appropriate credit to the original author(s) and the source, provide a link to the Creative Commons licence, and indicate if changes were made. The images or other third party material in this article are included in the article's Creative Commons licence, unless indicated otherwise in a credit line to the material. If material is not included in the article's Creative Commons licence and your intended use is not permitted by statutory regulation or exceeds the permitted use, you will need to obtain permission directly from the copyright holder. To view a copy of this licence, visit http://creativecommons.org/licenses/by/4.0/.

\section{References}

Ahmed MB, Zhou JL, Ngo HH, Guo WS, Thomaidis NS, Xu J (2017) Progress in the biological and chemical treatment technologies for emerging contaminant removal from wastewater: a critical review. J Hazard Mater 323:274-298. https://doi.org/10.1016/j.jhazmat. 2016.04.045

Bao CS, Zhao J, Sun YY, Zhao XL, Zhang XH, Zhu YK, She XL, Yang DJ, Xing BS (2021) Enhanced degradation of norfloxacin by Cemediated Fe-MIL-101: catalytic mechanism, degradation pathways, and potential applications in wastewater treatment. Environ Sci-Nano 8(8):2347-2359. https://doi.org/10.1039/d1en00250c

Bokare AD, Choi W (2014) Review of iron-free Fenton-like systems for activating $\mathrm{H}_{2} \mathrm{O}_{2}$ in advanced oxidation processes. J Hazard Mater 275(30):121-135. https://doi.org/10.1016/j.jhazmat.2014. 04.054

Chen JX, Gao NY, Lu X, Xia M, Gu ZC, Jiang C, Wang QF (2016) Degradation of 2,4-dichlorophenol from aqueous using UV activated persulfate: kinetic and toxicity investigation. RSC Adv 6:100056-100062. https://doi.org/10.1039/c6ra11166a

Chou YC, Lo SL, Kuo J, Yeh CJ (2015) Microwave-enhanced persulfate oxidation to treat mature landfill leachate. J Hazard Mater 284:83-91. https://doi.org/10.1016/j.jhazmat.2014.10.043

Fang GD, Gao J, Liu C, Dionysiou DD, Wang Y, Zhou DM (2014) Key role of persistent free radicals in hydrogen peroxide activation by 
biochar: implications to organic contaminant degradation. Environ Sci Technol 48:1902-1910. https://doi.org/10.1021/es4048126

Fang GD, Liu C, Gao J, Dionysiou DD, Zhou DM (2015a) Manipulation of persistent free radicals in biochar to activate persulfate for contaminant degradation. Environ Sci Technol 49:5645-5653. https://doi.org/10.1021/es5061512

Fang GD, Zhu CY, Dionysiou DD, Gao J, Zhou DM (2015b) Mechanism of hydroxyl radical generation from biochar suspensions: implications to diethyl phthalate degradation. Bioresour Technol 176:210-217. https://doi.org/10.1016/j.biortech.2014.11.032

Guan YH, Ma J, Li XC, Fang JY, Chen LW (2011) Influence of pH on the formation of sulfate and hydroxyl radicals in the UV/peroxymonosulfate system. Environ Sci Technol 45:9308-9314. https:// doi.org/10.1021/es2017363

Kluepfel L, Keiluweit M, Kleber M, Sander M (2014) Redox properties of plant biomass-derived black carbon (biochar). Environ Sci Technol 48:5601-5611. https://doi.org/10.1021/es500906d

Lau TK, Chu W, Graham NJD (2007) The aqueous degradation of butylated hydroxyanisole by $\mathrm{UV} / \mathrm{S}_{2} \mathrm{O}_{8}{ }^{2-}$ : study of reaction mechanisms via dimerization and mineralization. Environ Sci Technol 41:613-619. https://doi.org/10.1021/es061395a

Lee YJ, Radovic LR (2003) Oxidation inhibition effects of phosphorus and boron in different carbon fabrics. Carbon 41(10):1987-1997. https://doi.org/10.1016/s0008-6223(03)00199-4

Li DP, Zhao L, Cao XD, Xiao ZY, Nan HY, Qiu H (2021) Nickelcatalyzed formation of mesoporous carbon structure promoted capacitive performance of exhausted biochar. Chem Eng J. https:// doi.org/10.1016/j.cej.2020.126856

Liang LP, Xi FF, Tan WS, Meng X, Hu BW, Wang XK (2021) Review of organic and inorganic pollutants removal by biochar and biochar-based composites. Biochar 3:255-281. https://doi.org/10. 1007/s42773-021-00101-6

Liu HZ, Bruton TA, Doyle FM, Sedlak DL (2014) In situ chemical oxidation of contaminated groundwater by persulfate: decomposition by $\mathrm{Fe}(\mathrm{III})$ - and $\mathrm{Mn}(\mathrm{IV})$-containing oxides and aquifer materials. Environ Sci Technol 48:10330-10336. https://doi.org/ 10.1021/es502056d

Liu Y, Zhao Y, Wang JL (2021) Fenton/fenton-like processes with in-situ production of hydrogen peroxide/hydroxyl radical for degradation of emerging contaminants: advances and prospects. J Hazard Mater. https://doi.org/10.1016/j.jhazmat.2020.124191

Matzek LW, Carter KE (2016) Activated persulfate for organic chemical degradation: a review. Chemosphere 151:178-188. https://doi. org/10.1016/j.chemosphere.2016.02.055

Mckee DW, Spiro CL, Lamby EJ (1984) The inhibition of graphite oxidation by phosphorus additives. Carbon 22(3):285-290. https:// doi.org/10.1016/0008-6223(84)90172-6

Meng H, Nie CY, Li WL, Duan XG, Lai B, Ao ZM, Wang SB, An TC (2020) Insight into the effect of lignocellulosic biomass source on the performance of biochar as persulfate activator for aqueous organic pollutants remediation: epicarp and mesocarp of citrus peels as examples. J Hazard Mater. https://doi.org/10.1016/j. jhazmat.2020.123043

Nie MH, Yang Y, Zhang ZJ, Yan CX, Wang XN, Li HJ, Dong WB (2014) Degradation of chloramphenicol by thermally activated persulfate in aqueous solution. Chem Eng J 246:373-382. https:// doi.org/10.1016/j.cej.2014.02.047

Puziy AM, Poddubnaya OI, Socha RP, Gurgul J, Wisniewski M (2008) XPS and NMR studies of phosphoric acid activated carbons. Carbon 46(15):2113-2123. https://doi.org/10.1016/j.carbon.2008.09. 010
Qin CC, Wang H, Yuan XZ, Xiong T, Zhang JJ, Zhang J (2020) Understanding structure-performance correlation of biochar materials in environmental remediation and electrochemical devices. Chem Eng J. https://doi.org/10.1016/j.cej.2019.122977

Rayaroth MP, Oh D, Lee CS, Kang YG, Chang YS (2020) In situ chemical oxidation of contaminated groundwater using a sulfidized nanoscale zerovalent iron-persulfate system: Insights from a boxtype study. Chemosphere. https://doi.org/10.1016/j.chemosphere. 2020.127117

Reints W, Pratt DA, Korth HG, Mulder P (2000) O-O bond dissociation enthalpy in di(trifluoromethyl) peroxide $\left(\mathrm{CF}_{3} \mathrm{OOCF}_{3}\right)$ as determined by very low pressure pyrolysis. density functional theory computations on $\mathrm{O}-\mathrm{O}$ and $\mathrm{O}-\mathrm{H}$ bonds in (fluorinated) derivatives. J Phys Chem A 104(46):10713-10720. https://doi. org/10.1021/jp994434w

Shadi AMH, Kamaruddin MA, Niza NM, Emmanuel MI, Ismail N, Hossain S (2021) Effective removal of organic and inorganic pollutants from stabilized sanitary landfill leachate using a combined $\mathrm{Fe}_{2} \mathrm{O}_{3}$ nanoparticles/electroflotation process. J Water Process Eng. https://doi.org/10.1016/j.jwpe.2021.101988

Valero-Romero MJ, Garcia-Mateos FJ, Rodriguez-Mirasol J, Cordero $\mathrm{T}$ (2017) Role of surface phosphorus complexes on the oxidation of porous carbons. Fuel Process Technol 157(6):116-126. https:// doi.org/10.1016/j.fuproc.2016.11.014

Wu S, Fang GD, Wang YJ, Zheng Y, Wang C, Zhao F, Jaisi DP, Zhou DM (2017) Redox-active oxygen-containing functional groups in activated carbon facilitate microbial reduction of ferrihydrite. Environ Sci Technol 51:9709-9717. https://doi.org/10.1021/acs. est.7b01854

Wang XH, Zhang P, Wang CP, Jia HZ, Shang XF, Shang XF, Tang JC, Sun HW (2022) Metal-rich hyperaccumulator-derived biochar as an efficient persulfate activator: role of intrinsic metals $(\mathrm{Fe}, \mathrm{Mn}$ and $\mathrm{Zn}$ ) in regulating characteristics, performance and reaction mechanisms. J Hazard Mater. https://doi.org/10.1016/j.jhazmat. 2021.127225

Xie T, Reddy KR, Wang CW, Yargicoglu E, Spokas K (2015) Characteristics and applications of biochar for environmental remediation: a review. Crit Rev Environ Sci Technol 45:939-969. https:// doi.org/10.1080/10643389.2014.924180

Xu MH, Du HZ, Gu XG, Lu SG, Qiu ZF, Sui Q (2014) Generation and intensity of active oxygen species in thermally activated persulfate systems for the degradation of trichloroethylene. RSC Adv 4:40511-40517. https://doi.org/10.1039/c4ra04942j

Yang JP, Zhao YC, Ma SM, Zhu BB, Zhang JY, Zheng CG (2016) Mercury removal by magnetic biochar derived from simultaneous activation and magnetization of sawdust. Environ Sci Technol 50:12040-12047. https://doi.org/10.1021/acs.est.6b03743

Yang SY, Wang P, Yang X, Shan L, Zhang WY, Shao XT, Niu R (2010) Degradation efficiencies of azo dye acid orange 7 by the interaction of heat, UV and anions with common oxidants: persulfate, peroxymonosulfate and hydrogen peroxide. J Hazard Mater 179:552-558. https://doi.org/10.1016/j.jhazmat.2010.03.039

Yang SY, Xiao T, Zhang J, Chen YY, Li L (2015) Activated carbon fiber as heterogeneous catalyst of peroxymonosulfate activation for efficient degradation of acid orange 7 in aqueous solution. J Sep Purif Technol 143:19-26. https://doi.org/10.1016/j.seppur. 2015.01.022

Zhang YH, Yu JN, Li JL, Luo ZW (2017) Effect of nutritional needs on the yield of lignin-degrading enzyme and dyes decolourization using heterobasidion insulare. Fresen Environ Bull 26:5775-5782 